\section{A multiplicação dos media e a segmentação social $^{1}$}

\section{RESUMO}

Este artigo apresenta uma novidade em relação à "esfera pública burguesa" de Habermas. De acordo com 0 autor, a sugestão de Habermas é de que o período seguinte a sua tese, ou seja, o tempo atual, é essencialmente o de retorno do carisma da esfera pública representativa.

\section{ABSTRACT}

In this article, Katz takes a new stand towards Habermas' "burgeoise public sphere". According to the author, Habermas suggests that the period which follows the "burgeoise public sphere", that is, our time here and now, is essentialy the time of the return of the charisma which yields from the "representative public sphere".

\section{PALAVRAS-CHAVE / KEY WORDS}

- Burguesia (Burgeoise)

- Público (Public)

- Habermas (Habermas)

\section{Elihu Katz}

Prof. da Universidade da Pensilvânia/ EUA
AtÉ O MOMENTO, todos têm ouvido falar da "esfera pública burguesa", aquele momento da história na qual uma classe mercantil em ascensão sentiu-se em condições para deliberar sobre temas públicos, de forma racional e universal, e para transmitir suas conclusões aos poderes então vigentes com a expectativa de ser levada a sério. Sob o ponto de vista acadêmico, a tese de Habermas (1962/1989) tornou-se uma palavra cotidiana, talvez por oferecer uma recordação nostálgica de uma utópica democracia participativa, ou talvez porque ofereça a esperança de que algo ainda possa ocorrer - se simplesmente pudéssemos saber como fazer a segunda metade do século XVII adaptar-se às ostensivas condições da modernidade tornando-as compatíveis à educação ampliada, ao voto universal e às novas tecnologias de comunicação, fatores que parecem estar nos convidando a fazer tal tradução.

Mas esta não é a tese de Habermas na sua totalidade, nem sua parte mais original. O restante gira em torno da "esfera pública representativa" que se refere tanto ao período que a precedeu, como ao período que seguiu a nova fase da autônoma burguesia. No período inicial, refere-se à pessoa do monarca, pelo esplendor e carisma de sua regalia, símbolos da legitimidade de seu governo e unidade de seu poder. Esta também não é uma idéia nova.

O que é novo é a sugestão de Habermas de que o período seguinte à "esfera pública burguesa"- ou seja, nosso aqui e agora, é essencialmente o retorno do carisma da "esfera pública representativa", certamente não aquela do monarca absoluto, mas de uma instituição política e 
econômica que cercou-se de fazedores de imagens que lançavam o charme em nome da legitimidade e prerrogativas de seus clientes. ${ }^{2}$ Como afirma Calhoun (1992), sumarizando Habermas:

"Através destas transformações, a esfera pública tornou-se mais uma arena da publicidade do que um local para o debate crítico/racional. Os legisladores encenam papéis para seus constituintes. As organizações com interesses especiais usam a publicidade para aumentar o prestígio de suas novas posições, sem tornar os tópicos para os quais estas posições se referem temas de uma debate público genuíno. Os media são utilizados para criarem oportunidades aos consumidores de se identificarem com as posições públicas ou pessoais de outros. Tudo isso nos leva ao retorno da versão da publicidade representativa, a qual o público responde por aclamação, ou evitando a aclamação, em vez do discurso crítico."

Com este prefácio, este ensaio continuará em três partes. A primeira desenvolverá a idéia da esfera pública clássica, apoiando-se não tanto em Habermas, mas em outros, em especial no psicólogo social, Gabriel Tarde. Mostrarei como a concepção de Tarde da esfera pública se aplica não somente ao jornal mas talvez ainda mais à radiofonia. Direi algumas palavras sobre como o modelo europeu de radiodifusão pública se adapta tão bem (ou melhor, costumava se adaptar) a esta visão da esfera pública. Trarei informação recente de um estudo americano que testa empiricamente o esquema de Tarde.

A partir de então, mudarei o rumo. Ainda apoiando-me em Tarde, mas um diferente tarde, a Parte II mostrará um outro lado da mesma estória, focando mais na tecnologia dos media, e seus efeitos - não somente nos indivíduos mas nas instituições. Esta parte do argumento mostrará que os media, em sucessão - jornais, rádio, TV, internet - não contribuíram para a realização da democracia, mas para sua não-realização. Esta parte nos levará à discussão de nossa situação atual de uma televisão de multicanais em sinal aberto, via cabo, via satélite e a internet. Para antecipar o clímax desta Parte II, afirmo que nos encontraremos argumentando que os novos media não se destinam mais à naçào-estado e à esfera pública.

Na conclusão da Parte III tentaremos confrontar as tendências opostas das duas anteriores. Mas faremos isso num esforço de solução de um enigma em vez de ser uma declaração de uma convicção profunda. A verdade é que não sei as respostas.

\section{Parte I}

\section{A esfera pública de Gabriel Tarde}

A idéia de uma esfera pública na qual o governo é a referência de uma sociedade de cidadãos não se originou com Habermas, naturalmente. É essencialmente uma reafirmação da emergência de uma opinião pública na qual, na minha opinião, foi melhor caracterizado por Hans Speier (1950). Distinguindo opinião privada ou clandestina, de "opiniões apresentadas a outros", Speier concebe a opinião pública como um processo de comunicação de duas faces através dos quais (1) cidadãos deliberam entre si sobre temas de interesse público, e (2) transmitem estas deliberações ao governo. Como Habermas, Speier acrescenta que as pessoas que deliberam não devem ser elas próprias funcionárias do estado e que suas deliberações devem ser ancoradas numa crença partilhada tanto na liberdade de expressão como no direito de ser influente. O cruzamento da opinião com a comunicação também figura no bem 
conhecido interesse de Tocqueville (1935/ 1969) no associativismo americano, nas observações de Lord Bruce (1985/1991) sobre a imprensa e a conversação, e outros textos clássicos.

Meu favorito é Gabriel Tarde, o jurista francês, criminologista, e psicólogo social cujo ensaio do limiar-do-século, "Opinião e Conversação" (Tarde 1901/1989) referese a quatro elementos da esfera pública: a imprensa, a conversação, a opinião e a ação. Eu ouso dizer que Tarde não estava tão interessado numa teoria normativa da democracia, mas em observar como o comportamento coletivo era pressionado, estimulado, a servir a democracia. ${ }^{3}$ Há várias vantagens em apoiar-se em Tarde, mais do que em outros. Em primeiro lugar, ele sabe como a conversação se parece. Ao contrário de Habermas, Tarde refere-se aos tipos de conversação que realmente ocorriam em cafés, coffeehouses e salões. Eram conversações familiares, íntimas, trocas livres que ora se referiam e ora se afastavam de temas políticos, mas que não eram em hipótese alguma limitadas a eles. As conversações, notou Tarde, aconteciam entre pares que se assemelhavam, tanto em status e visões de mundo. Não eram o que Habermas considerava as situações ideais de fala; não envolviam "sustentação" de status ou o aceite de regras da razão antes de colocar o pé numa arena pública. Não se qualificariam igualmente para o que Michael Schudson (1997) chamaria de "conversa política", o que, em sua visão, é confrontacional, e freqüentemente dolorosa, conversa entre adversários ideológicos que tratam de legislação, como nos parlamentos. Por contraste, as conversas de Tarde são prazerosas, usualmente fáceis.

Uma segunda vantagem em referir Tarde é que ele trata os quatro elementos da esfera pública como um sistema linear tal como (1) a imprensa, tipicamente reportando sobre o governo, divulgando uma agenda de temas para a discussão (2) a pessoas reunidas nos cafés, coffehouses e salões onde tal diálogo ocorria. Estas conversações (3) filtravam as opiniões, clarificando-as enquanto elas moviamse de café em café e se cristalizavam em um ou duas opiniões públicas, e que se traduziam em ações. Por ação Tarde queria dizer a opção individual - o voto, por exemplo, mas também opções de consumo - e as reações do governo à opinião pública. A definição de Tarde de ação no nível individual é bem fraca, limitada ao seu aspecto de fazer escolhas, mas ele está consciente de como a representação da opinião consensual pela imprensa constitui o que ele chama de "trava ao governo".

Uma terceira vantagem de Tarde é que ele nos leva além de uma teoria funcionalista. Deste ponto de vista, a imprensa não é somente uma coletora de informação ou a supridora de agendas; é também uma agente poderosa na construção da nação. Tarde vê a imprensa como um agente essencial na integração nacional. A língua partilhada da imprensa e sua circulação define as fronteiras da nação, e a experiência partilhada de ler-se a agenda diária - com a consciência de que todos os demais de sua órbita estão fazendo a mesma coisa ao mesmo tempo - cria a sensação de nacionalidade, o que Benedict Anderson (1991) chama de "comunidade imaginada".

Tarde mostra que seu senso de comunidade partilhada também unificou 0 parlamento. Antes da imprensa, diz Tarde, os delegados de várias províncias tinham cada um deles o poder de veto sobre a aplicabilidade das regras e leis sobre seus constituintes particulares. À medida que a experiência comunitária cresceu, graças à imprensa, a regra de que o voto da maioria vale foi introduzida, tornando-se norma imposta a todos.

Aplicando Tarde a radiodifusão

Somente um quarto de século após a morte de Tarde, começou a era do rádio. 
No nível funcional, o novo veículo parecia ser um grande passo adiante no sentido da democracia participativa, realizando a promessa de simultaneidade a qual a imprensa havia aspirado, envolvendo os menos educados, e criando um novo foco de experiência partilhada da cultura e da política. Tanto os modelos americanos e britânicos de como o rádio deveria ser governado servia a estas funções. Os Estados Unidos licenciou estações isoladas que logo se estabeleceram como um pequeno número de redes comerciais para cobrir todo o país, fornecendo uma dieta de entretenimento, e finalmente de notícias, e de publicidade que pagava a conta.

Como é bem conhecido, a Inglaterra rejeitou explicitamente o modelo americano, graças a John Reith, que argumentava que o espectro eletromagnético era não só propriedade pública, mas potencialmente um serviço público que poderia construir a nação como uma comunidade partilhada de cultura e de discussão dos temas públicos. Foi Reith, praticamente só, que persuadiu o governo britânico a transformar o monopólio concedido inicialmente a uma associação de industriais do rádio numa autoridade pública de radiodifusão que ambicionava ser independente tanto do governo quanto do comércio (Briggs, 1961). A BBC foi um invento social importante. É impressionante o fato de que um governo deveria (por lei ou por convenção) voluntariamente ceder seu controle sobre as ondas em favor de um serviço de informação, educação e entretenimento operado por profissionais com orientação paternalista, supervisionada por uma direção apolítica dos bons e dos grandes tornando-se propriedade, de fato, de um público de acionistas que pagavam uma quase-taxa diretamente à Autoridade de Radiodifusão. É algo semelhante à idéia de uma universidade financiada por uma taxa pública, mas com mais riscos, já que a produção massiva de entretenimento e discurso crítico poderia, e às vezes ocorria, voltar-se contra o próprio governo.

Cardiff e Scannell (1987) descreveram graficamente como a recém-nascida BBC começou a inventar tradições que poderiam conectar várias regiões britânicas entre si na celebração de eventos religiosos e cívicos. Trouxe a periferia para o centro, e o centro para a periferia - na mensagem natalina anual do rei, por exemplo. Mesmo antes do estabelecimento do serviço noticioso radiofônico - quando as contrariedades dos jornais foram finalmente superadas, tanto nos Estados Unidos como na Inglaterra - o rádio era um poderoso agente de integração nacional, e em ambas as Guerras Mundiais, serviu como uma referência de união.

Depois da II Guerra Mundial, a televisão seguiu os passos do rádio como o veículo de integração nacional, levando o rádio a assumir seu novo papel de veículo segmentado e companhia de todo o dia das pessoas. Logo, havia estações de rádio para todas as idades, status, e grupos de interesse, ao mesmo tempo em que a televisão tomava a cena como o agente nacional da cultura e da política. Sobre as "objeções" da escola de Frankfurt (Horkheimer e Adorno, 1972) que temiam mais do que qualquer coisa a homogeneização da cultura de classes, a televisão fez exatamente isso: cometeu o crime de mesclar "Benny Goodman e o Quarteto de Cordas de Budapest" numa falsa consciência de unidade nacional, ou, se colocarmos a hegemonia de lado, numa fusão plana da identidade nacional.

A radiodifusão acabaria levando consigo as normas de balanceamento e imparcialidade para todos os lugares para onde se dirigiu. A instituição americana de debates pré-eleitorais é um exemplo de balanceamento racional/crítico que a televisão trouxe para a política. A idéia de que o eleitorado deveria ter uma boa idéia de quem são candidatos numa disputa eleitoral tornou-se agora virtualmente universal, e espalhou-se além mesmo das democracias. É possível afirmar que a democracia foi bem servida pela radiodifusão - tanto no rádio como na 
televisão - e que a radiodifusão pública, talvez especialmente em sua fase monopolística, proveu tanto a agenda e o fórum para a esfera pública.

\section{Exemplo empírico}

Embora tudo isso nos leve a pensar que o quadro descrito é belo - você não pensará assim em poucos minutos - eu posso documentar empiricamente que o sistema de Tarde funciona. Junto com Joohan Kim, meu aluno doutorando, e Robert Wyatt, nós mostramos, no caso dos Estados Unidos, que há uma clara relação linear entre a imprensa (ou seja, os media), conversação, opinião e ação. O resultado de nossa pesquisa nacional, publicada recentemente (Kim, Wyatt, Katz, 1999; Wyatt, Kim, Katz, 2000) demonstraram que a freqüência de leitura dos jornais, e em certa medida, a freqüência de audiência ao noticiário de TV, faz aumentar a conversação política (e até mesmo pessoal). Isso é correto quando se leva em conta em especial variáveis de contexto óbvias, e até mesmo de interesse político. Você não ficará surpreso em saber que os temas mais freqüentemente debatidos são crime e educação, seguido de economia, governo local e nacional, e em último lugar, noticiário internacional. Temas familiares, entretenimento e esporte foram os tópicos mais freqüentes de discussão superando inclusive o político. Você poderá ficar surpreso com o impacto que a audiência da TV tem em geral especialmente ao noticiário - ao aumentar tais conversações pessoais, mas não as conversações sobre política.

O locus de tais conversações - políticas assim como sobre temas pessoais - é o lar, seguido do local de trabalho e as organizações cívicas. Provavelmente, tal fato caracteriza o caráter familiar dos media, o ambiente protegido do lar, e, ainda, o fato evidente que os cônjuges começaram a falar sobre política. ${ }^{4}$ Isso significa, naturalmente, que a conversação política não é freqüentemente confrontacional; segue adiante entre os semelhantes. Além disso, nossas conclusões revelam que quando o crime e a educação são discutidas no lar, são deslocadas das referências políticas entrando no domínio pessoal. Em nosso estudo, restaurantes, bares e shopping centers - o equivalente atual dos cafés, não se constituíram em locais importantes para a conversação política; e nem a Internet.

Seguindo Tarde, podemos então perguntar se e como a conversação política afeta a opinião. A resposta é que ela aumenta o número de tópicos nos quais as pessoas têm opinião, e equipa os debatedores na sua oferta de mais razões na defesa de suas opiniões. Para nossa surpresa, a conversação aparentemente não aumenta a consistência das opiniões de um indivíduo.

Estas medidas de qualidade da opinião contribuem, mas não fortemente, à participação política tal como freqüentar encontros políticos, trabalhar em campanhas políticas, contatar candidatos por carta ou por telefone, e votar. A conversação política, por outro lado, é um fator de contribuição à participação política, ao lado de outros fatores determinantes como ser homem, com nível superior de renda, e atualizado no noticiário.

\section{Parte II}

\section{Outro olhar sobre Tarde}

Se revisarmos Tarde, encontraremos um outro Tarde, menos funcional, e muito mais preocupado com os efeitos dos media - o jornal, em seu caso - nas instituições. Em certa medida, poderemos inclusive dizer que Tarde é um teórico tecnológico, antecipando McLuhan (1964), Innis (1950) e Eisenstein (1979), mais interessado no veículo que na mensagem. Olhando para trás, já tivemos uma idéia de Tarde em sua discussão sobre o papel do jornal na 
integração nacional, tanto na nação como um todo, como no parlamento, onde o sentido de nacionalidade enriquecido pelo jornal constrangia o poder da maioria.

Mas Tarde dá um passo além neste papel, ao afirmar que o jornal derrubou a monarquia. Seu argumento está baseado na idéia de que somente o rei - o representante da esfera pública - tinha o conhecimento do que estava ocorrendo em vários vilarejos e regiões sob sua influência; ele tinha espiões e burocratas para lhe atualizar, e não tinha ele pressa alguma em deixar o Vilarejo A ao descobrir o que o Vilarejo B tinha em mente. O jornal minou o poder do rei, diz Tarde; tornou-o redundante.

Aplicando este Tarde aos media eletrônicos

Se aplicarmos esta linha de raciocínio aos media que sucederam o jornal - o rádio, televisão, e agora a internet - uma nova imagem emergirá, muito diferente do visto anteriormente. O rádio, depois a televisão, não só deslocaram o jornal sucessivamente como os media predominantes de integração nacional; eles não só serviram a esfera pública funcionalmente; eles também - como o jornal - corroeram as instituições de governança.

No caso do rádio, em primeiro lugar, podemos notar que os primeiros usuários do rádio - nos Estados Unidos e na Alemanha - foram Roosevelt e, mutatis mutandis, Hitler. Logo após subir ao poder no início dos anos 30, Roosevelt começou sua série de conversas ao pé da lareira, através do qual ele estabeleceu uma relação íntima com as famílias no lar que responderam, com afeto, a seu plano para o New Deal e, anos após, a sua tentativa de persuadir os americanos de que os Estados Unidos precisavam se comprometer a ter um papel ativo na Segunda Guerra Mundial. Observe-se que os apelos radiofônicos foram diretamente do presidente às pessoas, passando por cima do Congresso, criando uma liderança pessoal que por fim produziu o que passou a ser chamado, nos dias de Nixon, de "presidência imperial".

Hitler, naturalmente, foi além. Ele simplesmente fechou o parlamento e falou ao povo diretamente através de manifestações de massa e através do rádio. Os diários de Victor Klemperer (1998) nos dão uma idéia da cerimônia que cercava as exaltações de Hitler, e o temor do autor com sua efetividade. ${ }^{5}$ Ambos os homens inspiraram uma alta taxa de participação. Mas vemos aqui o início da erosão do ideal racional/crítico, e a fragilidade da intermediação do parlamento em favor do carisma do líder. $\mathrm{Na}$ verdade, se parece como a vingança do "rei". O jornal o derrubou, e o rádio o reinstalou.

Se aplicarmos este tipo de análise à televisão, vemos mais do mesmo tipo de escorregão institucional. Parece óbvio que a televisão terminou o que o rádio tinha começado. Trouxe a política para dentro. Embora Halin e Mancini (1984) tenham sugerido que as notícias de televisão façam com que os telespectadores italianos saiam à rua, em busca de discussão e interpretação - na piazza, nos sindicatos ou sedes partidárias - isso parece reforçar a proposta de Lazarsfeld e Merton (1948) de que as notícias radiofônicas, tipicamente, morrem na sala de estar. $\mathrm{Na}$ verdade, embora nossa própria pesquisa sugira que a conversação siga a audiência e que a conversação geralmente leva à ação política, muito ainda necessita ser feito para validar a imagem de que - lar é o espaço público, e que a ação política é um fenômeno disseminado. É muito cedo para abandonar a idéia de que a notícia radiofônica possa ter uma "função narcotizadora" na maior parte dos espectadores.

Uma formulação mais radical deste processo proporia que a televisão desintermediaria o partido político. As organizações partidárias de bairros praticamente desapareceram, a as 
lealdades políticas se enfraqueceram substancialmente no mundo ocidental. Há boas razões para se supor, no nível da ética dos media, que o equilíbrio da televisão, e sua imagem visual, tem algo a ver com isso - junto com mover a política para dentro, naturalmente. A enorme audiência dos debates pré-eleitorais, por exemplo, combate a atenção seletiva do dia anterior. Usualmente uma pessoa se manifestava, ou lia, ou ouvia somente o seu lado (Lazarsfeld et al., 1948), enquanto os debates televisivos convidam a atenção dos dois lados igualmente. $\mathrm{E}$ o que um vê e ouve é uma conversa muito centrada em $\mathrm{si}$, sons e imagens bem ensaiadas. Em conseqüência, os candidatos se parecem igualmente aceitáveis. Nenhuma afiliação partidária nem ideologia é exposta, e programas de ação se parecem.

Ostensivamente, a ausência de partidos políticos não significa que se esteja em choque com o discurso de Habermas, que apela para uma retórica da razão; mas é difícil dizer que as campanhas eleitorais contemporâneas, mesmo os debates televisivos, resumem a interação racional de onde as respostas ótimas para o bem estar comum emergirão. ${ }^{6}$ Habermas, que teme todo o tipo de representação (Peters, 1993), certamente concordaria. Calhoun (1992) cita-o dizendo que "a esfera gerada pelos mass media seguiu as trilhas de um segundo ambiente de intimidade." "Nós experienciamos a comunicação do rádio, filme e de televisão", na declaração de Calhoun, com uma rapidez muito maior que as características da palavra impressa. Um dos efeitos disso no discurso público é o de se "fixar" atributos pessoais tornando difícil se concentrar no argumento racional e crítico. Isso alimenta um sentimentalismo mais geral a pessoas e o correspondente cinismo a instituições, que limita a "capacidade subjetiva para a crítica racional da autoridade pública, mesmo onde isso seja objetivamente possível. Uma política personalizada revive a publicidade representativa ao tornar candidatos em estrelas dos media."

Portanto, da mesma forma que o jornal derrubou o rei, o rádio desintermediou o parlamento em favor do líder eleito, e a televisão minou o partido político, em favor da personalidade do político. O que virá depois?

\section{A nova tecnologia dos media}

As novas tecnologias dos media têm uma característica excepcional: eles não fornecem um veículo para os fins da integração nacional. De um ponto de vista tecnológico determinista - ou seja, se os media afetam as instituições políticas na forma como examinamos - a nação está ficando fora de nosso campo de visão.

Como assim? Em primeiro lugar, estamos testemunhando a morte da televisão como a conhecemos devido à incrível multiplicação dos canais graças à capacidade dos cabos e satélites, mais a capitulação dos governos baixo o comando dos barões dos media. É irônico ver governos conservadores, aparentemente comprometidos com o patriotismo, sucumbir às tentações do sistema da radiodifusão e minando a centralidade da radiodifusão pública. $O$ escândalo e o sensacionalismo parecem sub-produtos desta competição populista, e as notícias serão logo deslocadas do horário nobre. $\mathrm{Na}$ verdade, estamos testemunhando uma profunda crise na radiodifusão pública em todos os lugares. Tendo que enfrentar a cruel escolha entre tornar-se um canal de elite para um limitado grupo da audiência política e culturalmente mobilizada, ou um canal de massa que dificilmente é diferente de seus competidores privados, é muito difícil continuar.

Ainda mais impressionante é a proliferaçào de canais segmentados, destinados a audiência étnicas e religiosas, ou para audiências interessadas somente em esporte, ou arte, ou notícias - mas distante da maioria da população. A arena 
central, o fórum público nos quais os tipos de pessoas podem falar para, ou pelo menos ouvir a, estão desaparecendo. Tanto a mera multiplicação dos canais, e agora a ascensão de canais especializados, estão mudando o caráter do espaço público. A televisão não está mais nos unindo; é um veículo diferente, mesmo se continuarmos a dar-lhe como antes os $40 \%$ de nosso tempo de lazer.

E agora a internet está em rápida ascensão como o veículo predominante de comunicação, mas não como o veículo de integração nacional. Pela primeira vez em 100 anos, a nação está fora de foco. Com todo seu magnífico potencial, a internet é acionada em direção das redes transnacionais de comunicação - diásporas, se quisermos, e outros interesses especiais - assim como a intimidade da comunicação privada. Combinada com a capacidade da radiodifusão, tem seu potencial de chegar a uma audiência nacional, mas é improvável que o faça, ou pelo menos é isso que me parece.

Se alguém desejar resumir a aparente "teleologia" dos media existentes, poder-seia dizer que existem duas tendências - uma em direção à individualização, a outra em direção à globalização. Individualização significa que os novos media podem combinar-se assim como suas mensagens para paladares altamente individualizados: pode-se montar o jornal que se quer ("tudo menos o Oriente Médio", por exemplo), ou o programa para os gostos de um subgrupo. Globalismo significa que certas mensagens e gêneros - a Copa do Mundo, ou o Papa, ou "Dallas"- podem captar a todos em todos os lugares. Observe-se que em nenhuma destas tendências há espaço para a nação-estado. Podemos acrescentar agora a nação, além do parlamento, partido e nação, à lista de instituições democráticas minadas pelos media eletrônicos - mesmo aquelas que contribuem para a participação democrática.

\section{Parte III}

\section{Onde estamos?}

Bem vindos ao pós-modernismo. É muito difícil decidir onde está a realidade. De um lado, temos algumas evidências de que a esfera pública está funcionando. Do estudo americano que relatei, parece que as pessoas mantém-se atualizada sobre política; elas não são tão ignorantes como pensávamos. Elas lêem jornal e vêem televisão. Elas falam com outras pessoas, se relacionam com elas, apesar do efeito de ressonância de Putnam (1995). ${ }^{7}$ Elas formam opinião sobre os temas da atualidade. Elas atuam - embora somente uma minoria fazem mais do que votar, e mesmo o ato de votar está em declínio. ${ }^{8}$ Menos da metade dos americanos apresentam-se às mesas de votação nas eleições nacionais; um número maior assiste os debates pré-eleitorais na TV.

Por outro lado, vemos que as instituições da democracia participativa estão falhando, e talvez os media são parcialmente responsáveis. A radiodifusão, e agora a internet, alcança as pessoas em suas casas, passando por cima dos parlamentos, os partidos políticos, e até mesmo das nações. Gostaríamos de que os media fossem uma voz independente, e para prover um plataforma, mas numa certa comunidade constituída, e não numa sociedade amorfa que oferece um sensação ilusória de poder. A mensagem é consumismo, o entretenimento cínico do escândalo político, as relações públicas dos estabelecimentos, e as seduções do globalismo. É verdade, a internet provê mais do que oportunidade para reação e participação - é um grande veículo para a organização de grupos de pressão - mas muito poucos usuários parecem gastar tempo com a cidadania quando estão a postos. E o consumismo é um fenômeno crescente também aqui.

Quero explorar duas implicações que emergem desta discussão, assim como desejo oferecer ambas não como 
conclusões mas como enigmas, e dilemas para a teoria e a pesquisa.

Enigma Um pode ser chamada de Cidadãos Sem Democracia, ou numa forma mais familiar, Cidadãos Sem Nação. Este título reverte a Democracia sem Cidadãos de Robert Entman (1989), que implica que o sistema funciona razoavelmente bem, mesmo sem muita participação; argumenta, ao contrário, que há participação, ou que se parece com participação, mas que seu enquadramento teve um colapso. Há muitas pessoas navegando nas águas da política participativa, mas não estão indo a lugar algum. O conceito de "disfunção narcotizante" de Lazarfeld e Merton sumariza este tipo de ritualismo ao apontar ao consumidor pesado de notícias que se engana ao acreditar que está envolvido em política, mas sua atenção, mesmo suas opiniões, não vão além da sala de estar. Há um curto circuito, em outras palavras. Muitos cidadãos estão assumindo suas responsabilidades, ou tentando, mas seus mecanismos de comunicação e gregarismo de alguma forma se desgastaram.

O elo faltante são as instituições: as organizações voluntárias, os sindicatos, os partidos políticos, o parlamento que, ironicamente, estão se tornando psicologicamente cada vez mais distantes, mesmo se a comunicação com eles é ostensivamente mais fácil, e não mais difícil. As instituições políticas estão fragilizadas, e a esfera pública - como corporificadas na mídia, ao menos - está sendo comercializada, dirigindo-se a audiências em vez de se dirigir a cidadãos. Apesar de Inglehart, o egoísmo e o materialismo estão difundidos; os shopping centers afastaram o público da praça, do encontro comunitário, dos parlamentos e dos partidos políticos. As pessoas têm mais confiança nas organizações comerciais do que nas políticas, incluindo o jornalismo (Wyatt, não publicado). Parece que estamos retornando ao modelo clássico da sociedade de massas onde líderes carismáticos e massas tinham acesso direto entre sí (Kornhauser, 1959). Agora, até mesmo os líderes perderam sua autoridade moral...

Talvez uma das Partes esteja simplesmente errada. Uma revisão das evidências nos sugerem que a Parte I - da participação do cidadão - está melhor amparada, mas a Parte II - o fracasso institucional - é mais convincente. Se ambos estiverem certo, como é que as duas partes deste enigma podem ser reconciliados ? Existe uma melhor maneira?

O Enigma Dois está relacionado. Sua preocupação última é com o futuro da radiodifusão pública. Ele argumentará, da parte I, que os cidadãos fortalecerão a radiodifusão pública, e da parte $\mathrm{II}$, que as instituições para realizar isso estão fora do alcance, ou não-existente.

A maneira de pensar sobre isso, em minha opinião, é observar a relação simbiótica existente entre a estrutura dos media e a estrutura da sociedade, sem pré julgar (como a Parte II tendia fazer) o que vem antes. Israel é o caso que eu melhor conheço. Durante a fase fortemente coletivista da construção nacional da sociedade, havia vários movimentos sociais, cada um deles militando em torno de um jornal, buscando um objetivo comum em formas radicalmente diferentes, mas unidas em torno da monopólio da radiodifusão, primeiro o rádio e depois a televisão. Durante os dias da era do rádio, as pessoas acompanhavam as notícias a cada hora, e as discutiam nas ruas, no trabalho, na comunidade, no partido e nas reuniões sindicais, e em casa. A televisão unia a todos - todos mesmo, ou quase todos - no noticiário das nove da noite; era uma regra não escrita não fazer chamadas telefônicas durante estes 30-40 minutos, e estar preparado para discutir a agenda na próxima manhã de domingo. Com grande segurança e prosperidade, o materialismo e a o egoísmo ganharam terreno; isso se refletiu com a ascensão das instituições de promoção do consumo, e, em paralelo, 
na introdução de um segundo canal comercial baseado na publicidade. ${ }^{9}$ Mais tarde, quando as tendências separatistas começaram a desmontar o pluralismo e o multiculturalismo, nós observamos a ascensão de canais de radiodifusão especializados, e um recuo gradual dos canais de sinal aberto. A maior parte da audiência, como insiste Curran (1998), ainda é dos dois canais abertos, mas suspeito que gradualmente desaparecerá - a não ser que uma crise, ou melhor ainda um jogo de basquete, nos faça outra vez uma nação. A estrutura da nação e os media estão intimamente relacionados - não somente em Israel. Considere os Estados Unidos versus a Inglaterra, ou a Holanda, ou a Bélgica.

A verdade é que um forte sistema de radiodifusão pode manter uma nação unida. Mas devemos agora acrescentar, somente se ela desejar permanecer unida. Apesar do sabor tecnológico deste ensaio, temo em afirmar que esse último fator seja pré-requisito para o anterior. Um serviço de radiodifusão pública significa afirmar que se "toma conta da nação".

Permitam-me reiterar o que quero dizer, ou costumava dizer, por radiodifusão pública. É um sistema de media (1) baseado numa sociedade de acionistas - a cidadania que possui, ou sente que possui, o sistema. É (2) administrado por um Conselho de pessoas criativas e confiáveis, com sensibilidade cívica, que o protege cuidadosamente da interferência do governo e do comércio. É (3) tocada por profissionais cujo lema é que o consumidor - ou seja, o cidadão - não está sempre certo, mas precisa ser bem servido. Sua programação é guiada (4) pelo critério de qualidade e relevância, com um olho na continuidade das culturas da nação e dos grupos que a constituem, (5) com a preocupação da diversidade de expressão - mesmo com programas noticiosos que competem entre si, por exemplo, e (6) com o compromisso de difundir notícias e temas públicos no horário nobre. Seu cerne é (7) que a pluralidade dos grupos e interesses que constituem a sociedade se vejam e se ouçam na mesma arena - em temas cívicos e de cultura - além das vozes profissionais de comunicadores e especialistas. Disso segue (8) que o canal é visto mais ou menos por todos. Incidentemente, esta é a razão pela qual pode-se argumentar que o sistema de monopólio público - a sociedade de um canal- pode ser mais democrático do que outro de vários canais.

Repito, para se reinstalar este tipo de sistema de radiodifusão requer-se aparentemente um compromisso renovado com a idéia de nação. Certamente pluralista, mas uma comunidade imaginada com identidade partilhada juntamente com as instituições que a fazem funcionar.

Identidades transnacionais, interesses multinacionais, e tecnologias de comunicação talvez estejam fazendo a nação supérflua. Em decorrência, o desejo da nação pode se enfraquecer. Novas formas de arranjos sociais podem estar sendo feitas para se constituir novas formas de identidade e novas estruturas de participação que deslocará o tipo de aliança e investimento - emocional e racional - que acompanham a cidadania nacional. A nação pode ser reduzida a uma mera unidade administrativa, definida geograficamente por conveniência. Talvez isso possa produzir até mesmo um mundo melhor, um mundo que nos afaste de um nacionalismo excessivo.

O enigma que encerro é se existe alguma outra forma de reinstalar o tipo de radiodifusão pública que se adapte ao aparente desejo de se ter uma democracia participativa, e se a idéia de reparar-se a nação reparando-se o sistema público de radiodifusão é pedir demais .

\section{Notas}

1 Este é um ensaio entre outros que procura desenvolver conceitos para tratar as implicações sociais das novas 
tecnologias de comunicação. Os ensaios anteriores publicados incluem Katz (1992), Katz (1196), Katz (1998b).

2 Daniel Boorstin (1964) foi um dos primeiros a referir-se a este tema.

3 Sobre o desenvolvimento do pensamento de Tarde, especialmente a transição para públicos, ver Clark (1969), Hoscovici (1985) e Van Ginneken (1992).

4 Sobre o desenvolvimento do pensamento deTarde, especialmente a transição para públicos, ver Clark (1969), Hoscovici (1985) e Van Ginneken (1992).

5 Em uma passagem, Klemperer (1998) expressa sua surpresa de que 0 discurso de Hitler não comandava a tenção do público.

6 Há, no entanto, muito 0 que se dizer em defesa de tais debates. Ver Kraus (1962).

7 Vários estudos discordam seriamente da generalização de Putnam de que há um declínio de filiação organizacional nos Estados Unidos. No entanto, sua tese tem atraído amplo interesse e, pareceu convincente a muitos.

8 Michael Schudson (1998) e outros teóricos estão menos convincentes sobre o declínio da cidadania participativa, se é que existe uma. Eles acreditam que a democracia participativa localiza o debate político ao seu próprio e natural local, no parlamento, e que os cidadãos devem supervisionar a performance de seus representantes e dar-lhe o apoio, ou retirar, nas eleições.

9 Joseph Ben-David mostra que a súbita ascensão do número de advogados reflete o crescimento do individualismo e da propriedade como valores em Israel.

\section{Referências}

ANDERSON, Benedict (1991). The Imagined Community: Reflections on the Origin And Spread of Nationalism. London: Verso.

APPADURAI, Arjun (1996). Modernity at Large. Minneapolis; University of Minnesota Press.
BOORSTIN, Daniel (1964). The Image: A Guide to Pseudo Events in America. New York and Row.

BRIGGS, Asa (1961). History of Broadcasting in the United Kingdom. Vol.1: The Birth of Broadcasting. Oxford.

BRYCE, James (1985/1991). The American Commonwealth. New York: MacMillan.

CALHOUN, Craig ed. (1992) Habermas and the Public Sphere. Cambridge, Ma: MIT Press.

CARDIFF, David and Paddy Scannell (1987). "Broadcasting and National Unity." In J. Curran, A Smith and Pauline Wingate, eds., Impact and Influences: essays on Media Power in the Twentieth Century. London: Methuen.

CAREY, James (1967). "Harold Adams Innis and Marshall McLuhan", Antioch Review, 27(1): 5-39.

CLARK, Terry, ed. (1969). Gabriel Tarde on Communication and Social Influence. Chicago: University of Chicago Press.

CURRAN, James (1998). "Crisis of Public Communication: a reappraisal ". In T. Liebes and J. Curran, eds., Media, Ritual, Identity. London: Routledge.

DETOCQUEVILLE, Alexis (1835/1969). Democracy in America (J.P. Maier, Trans). Garden City, NY: Anchor Books.

EISENSTEIN, Elisabeth L. (1979) The printing press as agent of change. Cambridge: Cambridge University Press.

ENTMAN, Robert (1989). Democracy Without Citizens. New York: Oxford.

FREIDSON, Eliot (1953). 'The Relation of the Situation of Contact to the Media In Mass Communication", Public opinion Quarterly, 17: 230-238.

GITLIN, Todd (1998). "Public Sphere or Public Spherecules". In Tamar Liebes and James Curran, eds., Media, Ritual, Identity. London: Routledge.

HABERMAS, Jurgen (1962/1989). The Structural Transformation of the Public Sphere:an Inquiry into a Category of Bourgeois Society (T. Burger, trans). Cambridge, Ma: MIT Press. 
HALLIN, Daniel \& Paolo MANCINI. "Speaking of the President: Political Strucuture and representational form in US and Italian television News", in Theory and Society. V. 13, no. 6, november 1984.

HANDELMAN, Don and Elihu Katz (1990) "State Ceremonies of Israel.", in Don Handelman, Models and Mirrors: Towards na anthropology of Public Events. New York: Cambridge University Press, 191-233.

HORKHEIMER, Max and Theodore Adorno (1972). Dialetic of Enlightenment. New York: Continuum.

INNIS, Harold (1950). Empire and Communication. Toronto: University of Toronto.

KATZ, Elihu (1988). "Desintermediation: Cutting out the Middle Man", Intermedia, 16: 30-31.

.Elihu (1992). "Individualisation, segmentation. Mondialisation: la technologie de la television et létatnation", in A. Caron and P. Juneau, eds., Le defi des Televisions nationales a l'ere dela mondialisation. Montreal: Presses deL'Universite de Montreal, 133-144.

.Elihu (1996). "And Deliver us from segmentation". Annals of the American Academy of Political and Social Science. July 96.

.Elihu (1998b) "Mass Media and Particpatory democracy", in T. Inoguchi et al. (eds.), The Changing Nature of Democracy. Tokyo: UN University Press.

KATZ, Elihu and hanna Adoni (1973). "Functions of the Book for Society and Self" Diogenes, 81.

KATZ, Elihu, Sharon DOKTER, Jodi GUSEK, Miriam METZGER, Jaqueline O'CONNELL, and Jane STOKEr (1998). "Press Conversation-Opinion-Action: Gabriel Tarde's Public Sphere", in J. Lautman and B. Lecuyer, eds., Paul Lazarsfeld (1901-1976): la Sociologie de Vienne a New York. Paris: L'Harmattan.

KATZ, Ruth and Elihu Katz (1998). "McLuhan: Where did he come from, where did he disappear?" Canadian Journal of Communication, 23(3): 307-319.

KIM, Joohan, Robert Wyatt, and Elihu Katz (1999). "News, Talk, Opinion, Participation: The Part played by conversation in Deliberative Democracy", in Political
Communication, 16(4): 361-386.

KLEMPERER, Victor (1998). I will bear witness: a diary of the nazi years: 1933-1941. Vol.1 (trans Martin Chalmers). New York: Random House.

KORNHAUSER, William (1959). The politics of mass society. Glencoe, IL: Free Press.

KRAUS, Sidney (1962) The Great Debates. Bloomington, Indiana University Press.

LAZARSFELD, Paul F., Bernard BERELSON, and Hazel GAUDET (1948). The People's Choice. New York: Columbia University Press.

LAZARFELD, Paul F., and Robert K. MERTON (1948). "Mass Communication, Popular Taste and Organized Social Action", in L. Bryson, ed. The Communication of Ideas. New York: Harper.

MCLUHAN, Marshall (1964). Understanding Media: The Extensions of Man. New York: McGraw-Hill.

MOSCOVICI, Serge (1985). The age of the crowd. Cambridge: Cmabridge University Press.

PETERS, John D. (1993). "Distrust of Representation: Habermas and the Public Sphere", in Media, Culture and Society, 15(4): 541-57.

POSTMAN, Neal (1986). Amusing ourselves to death: public discourse in the age of Show Business. London: Heinemann.

PUTNAM, Robert (1995). "Bowling Alone: America's Declining Social Capital", in Journal of Democracy, 6: 65-78.

RIESMAN, David, Reuel DENNY and Nathan GLAZER (1950). The lonely crowd. New Haven: Yale University.

RUSSO, Michael (1983). CBS and the American political experience: a history of the CBS News Special Events and Elections Unit 1952-1968. Ann Arbor: University Microfilms.

SHOLEM, Gershom (1973). Sabbatai Tzvi: the mystical messiah (trans. R.J.Z. Werblowski). Princeton: Princeton University Press. 
SCHUDSON, Michael (1997). "Why conversation is not the soul of democracy?", inCriticial studies in Mass Communication, 14: 297-309.

.Michael (1998). The Good Citizen. Cambridge, MA: Harvard University Press.

SPEIER, Hans (1950). "On the historical development of public opinion", in American Journal of Sociology, 55: 376-388.

TARDE, Gabriel (1880/1903). The laws of imitation (trans. Elsie Clews Parsons). New York: Henry Holt.

.Gabriel (1901/1989). L'Opinion et la foule. Paris: Presses Universitaires de France.

VAN GINNEKEN, Jaap (1992). Crowds, Psychology and Politic: 1871-1899. Cambridge: Cambridge Univeersity Press.

WOLF, Kurt, ed. (1950). The sociology of George Simmel. Glencoe: Free Press, 85-177.

WYATT, Robert, Joohan Kim and Elihu Katz (2000). "Building the spheres: political and personal conversation and private spaces", in Journal of Communication, 50: 1, 71-92. 